\title{
Electrochemical Evaluation of the Chitosan-Gelatin Biopolymer as a Detached Film with a Body Simulated Physiological Solution
}

\author{
J.L. Ramírez, ${ }^{a, *}$ H. Quintana ${ }^{a}$, G. Galicia ${ }^{a}$ and T. Hernández ${ }^{b}$ \\ ${ }^{a}$ Instituto de Ingeniería-Universidad Veracruzana, SS Juan Pablo II s/n, Zona Universitaria, \\ Boca del Río, Veracruz, CP 94294, Mexico \\ ${ }^{b}$ Centro Microna, Universidad Veracruzana, Av. Ruiz Cortinez s $/ n$, Zona Universitaria, Boca \\ del Río, Veracruz, CP 94294, Mexico
}

Received December 8, 2017; accepted May 30, 2018

\begin{abstract}
Biomaterials are being used in implants as metallic supports, to restructure bone and tissue in biomedical applications, and so forth. In this study, the assessment of films from the Chitosan-Gelatin system in detached conditions was carried out, in order to evaluate the effect of the electrolyte over the membrane, to simulate a physiological solution. An equivalent circuit is proposed, so as to interpret the process of biopolymer degradation using electrochemical parameters, as well as a reaction mechanism for the membrane's cathodic areas. The gathered information may be associated with the biodegradability ionic diffusion behavior, also in its application as a temporary coating for metal protection control during the corrosion process of biomaterials, such as magnesium, in bone regeneration.
\end{abstract}

Keywords: chitosan, detached film, diffusion, electrochemistry, impedance.

\section{Introduction}

The viscoelasticity, biodegradability and biocompatibility properties of the chitosan-gelatin biopolymer have made it a material of scientific interest in the biomedical area, regarding prosthesis, sensors applications, etc. [1-3]. The conductivity type of pure chitosan is ionic, and it is due to the presence of free amino groups, and to the absorption of environmental humidity, allowing it to increase its conductivity; the protonation of amino groups, which leaves free hydroxyl ions in water, can modify chitosan ionic conductivity. Chitosan is also known for its hydrophilic properties. Little absorbed moisture is sufficient to modify the crystallinity degree that produces molecular relaxation efforts,

\footnotetext{
* Corresponding author. E-mail address: luiramirez@uv.mx
} 
resulting in the physicochemical properties that control chitosan biodegradation processes which also are characteristic [4-6].

Electrochemical methods, such as electrochemical impedance spectroscopy (EIS), have been used as a very effective tool, in order to carry out interfaces assessments, either in very high frequencies, so as to determine dielectric properties of polymeric materials, or in medium and low frequencies, in the electrochemical degradation phenomena in the aqueous phase [7-8]. This technique is widely used to study interface processes, the reaction mechanisms controlled by diffusion [9], corrosion mechanisms [10], formation of corrosion products that influence the resistance of micro-pores, capacitances of coating films and double electric layers, water up-take and other applications that are being developed.

The following expressions have been proposed to correlate the impedance response in the maximum value conditions of the imaginary diffusion impedance $\mathrm{Z}_{\omega(\max )}$ occurring at the maximum frequency angle $\omega$ (max).

$$
\begin{gathered}
Z_{w}=0.59 * \sigma * \delta * D^{1 / 2}=0.42 * R_{d} \\
\sigma=1.06 * Z * Z^{*}(\max )^{*} \omega_{\max }{ }^{1 / 2} \\
\omega_{\max }=2.54 *\left(D * / \delta^{2}\right)
\end{gathered}
$$

where $\mathrm{Z}_{\mathrm{w}}$ is the Warburg diffusion impedance, $\delta$ is the film thickness, $\sigma$ is the Warburg diffusion coefficient, and $\mathrm{D}$ is the diffusion coefficient of the electroactive species through the porous film [12].

The circuit admittance $\left(\mathrm{Y}_{0}\right)$ is the reciprocal of the impedance value, and it is a parameter of importance in mathematical calculations involving equivalent circuits applied for the adjustment of models from experimental data obtained using EIS techniques; correlations that relate it to the limited diffusion phenomena and interface thickness have been described in literature [11-12,14$15,22]$. Basically, it is expressed as it follows:

$$
Y_{0}=\left(R_{d}\right)^{-1} \text { and } B=\delta / \sqrt{D}
$$

Diffusion occurs when an electrochemical response involves charge transfer mechanisms; compared with charge transfer mechanisms, they are slower $[11,13]$.

Then, combining expressions (1) to (4), we obtain equation (5), employed to determine the Warburg diffusion coefficient, which is expressed as follows, with $\Omega-\mathrm{cm}^{2} \mathrm{~s}^{-1 / 2}$ units:

$$
\sigma=1 *\left(\sqrt{ } 2 * \mathrm{Y}_{0} * \mathrm{~B}\right)^{-1}
$$

where $\mathrm{Y}_{0}$ is the admittance, and in turn, is the inverse of the limited diffusion resistance $\left(R_{d}\right)$, and equivalent to the $O$ parameter value, and $B$ is a coefficient that contains the sample's physical dimensions, which are included in the equivalent circuit shown in Fig. 1 [15].

In electrochemical systems, every real system has its equivalent circuit, which does not only differ in the extent of its components, but also in the number and 
ways to combine them; for instance, $R_{s}$ represents the electrolyte resistance, $R_{f}$ is the polymer film resistance, $C_{f}$ is the polymeric film capacitance, $R_{c t}$ is the charge transfer resistance, and $\mathrm{C}_{\mathrm{dl}}$ is the double-layer.

The equivalent circuit applied to this electrochemical system is shown in Fig. 1, where $R_{s}$ is the electrolyte resistance, $C_{f}$ is the membrane capacitance, $R_{f, c}$ is the membrane cathodic resistance, $\mathrm{R}_{\mathrm{f}, \mathrm{a}}$ is the membrane anodic resistance, $\mathrm{O}_{\mathrm{c}}$ is the finite cathodic diffusion response and $\mathrm{O}_{a}$ is the anodic finite diffusion response across the membrane.

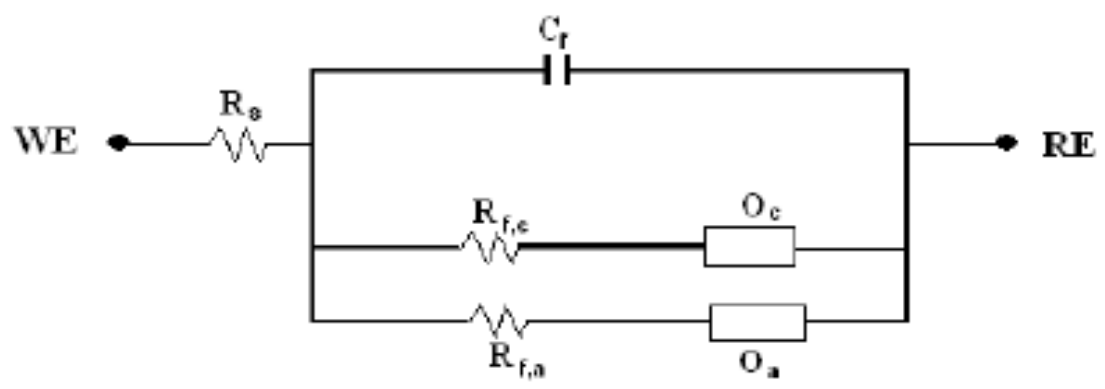

Figure 1. Equivalent circuit used for adjusting the results of the Chitosan-Gel membrane.

When a polymer membrane is exposed to an aqueous medium or water vapour, it enters the polymer structure and increases its volume, due to the water high permittivity $(\epsilon=80)$, and manifests itself both in the permittivity $\left(\epsilon^{\prime}\right)$ and capacitance $\left(\mathrm{C}_{\mathrm{m}}\right)$. Kingsbury et al. [16-17] proposed a correlation to determine the water incorporation in mixtures, which is shown in equation (6).

$$
X_{V}=100 \log \left(\frac{c_{m}}{c_{m, 8}}\right) / \log (80)
$$

where $\mathrm{X}_{\mathrm{v}}$ is the $\%$ in volume of up-taken water by the polymer structure, $\mathrm{C}_{\mathrm{m}}$ is the measured capacitance during exposure, and $\mathrm{C}_{\mathrm{m} .0}$ is the capacitance at the zero- time exposure.

\section{Experimental methodology}

For the preparation of the Chitosan-Gelatin films, the Aldrich ${ }^{\circledR}$ reagent was used; it was diluted in citric acid $1 \%(\mathrm{w} / \mathrm{v})$ with $4 \mathrm{rev} / \mathrm{min}$ of agitation. Afterwards, the $\mathrm{pH}$ was neutralized with $0.1 \mathrm{M} \mathrm{NaOH}$, and rinsed 3 times with distilled water; then, it was solidified employing an evaporation method for 8-12 hours in the oven, at $60^{\circ} \mathrm{C}$, obtaining an average of $180 \pm 20 \mu \mathrm{m}$ in thickness [18]. The arrangement shown in Fig. 2 was used for the electrochemical evaluation. It was carried out using a polymethyl methacrylate (PMMA) cylindrical cell of 2 compartments with $200 \mathrm{~mL}$ of a Kokubo physiological solution [19-20], each at $\mathrm{pH} 7.2$, as seen in Table 1.

Among these, a sample of the Chitosan-Gel film was added at $\mathrm{pH} 6$, with an exposure area of $6.15 \mathrm{~cm}^{2}$. 


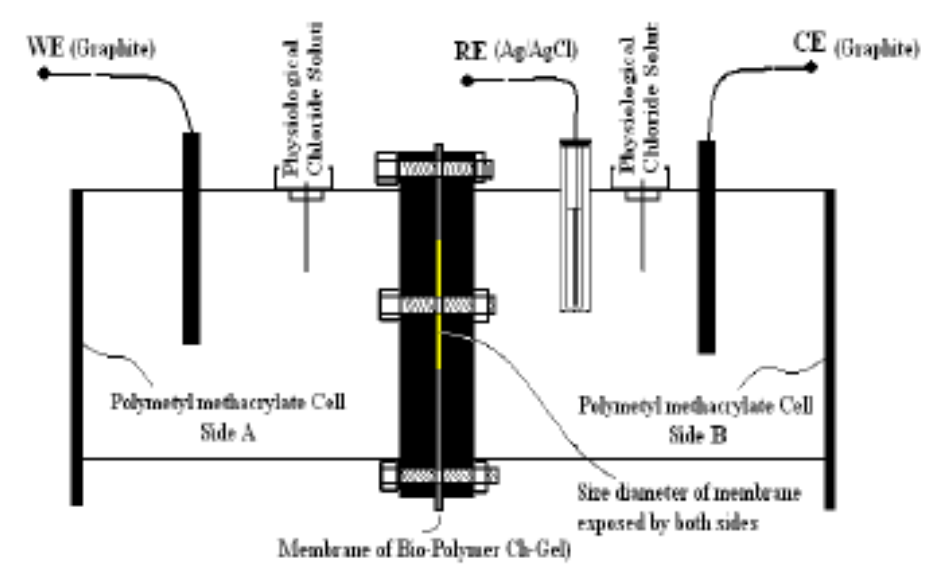

Figure 2. Electrochemical cell used to evaluate membranes as detached films.

Table 1. Chemical composition of the Body Simulated Kokubo Solution [19].

\begin{tabular}{|c|c|c|c|}
\hline No & Reactive & Quantity & Essay, min \\
\hline 1 & $\mathrm{NaCl}$ & $7.996 \mathrm{~g}$ & $99.5 \%$ \\
\hline 2 & $\mathrm{NaHCO}_{3}$ & $0.350 \mathrm{~g}$ & $99.5 \%$ \\
\hline 3 & $\mathrm{KCl}$ & $0.224 \mathrm{~g}$ & $99.5 \%$ \\
\hline 4 & $\mathrm{~K}_{2} \mathrm{HPO}_{4} \cdot 3 \mathrm{H}_{2} \mathrm{O}$ & $0.228 \mathrm{~g}$ & $99.0 \%$ \\
\hline 5 & $\mathrm{MgCl}_{2} \cdot 6 \mathrm{H}_{2} \mathrm{O}$ & $0.305 \mathrm{~g}$ & $98.0 \%$ \\
\hline 6 & $1 \mathrm{kmol} / \mathrm{m}^{3} \mathrm{HCl}$ & $40 \mathrm{~cm}^{3}$ & $87.28 \mathrm{~mL}$ of $\mathrm{HCl} 35.4 \%$ diluted in $1000 \mathrm{~mL}$ \\
\hline 7 & $\mathrm{CaCl}_{2}$ & $0.278 \mathrm{~g}$ & $95 \%$ \\
\hline 8 & $\mathrm{Na}_{2} \mathrm{SO}_{4}$ & $0.071 \mathrm{~g}$ & $99.0 \%$ \\
\hline 9 & $\left(\mathrm{CH}_{2} \mathrm{OH}\right)_{3} \mathrm{CNH}_{2}$ & $6.057 \mathrm{~g}$ & $99.9 \%$ \\
\hline 10 & $1 \mathrm{kmol} / \mathrm{m}^{3} \mathrm{HCl}$ & Adjusted $\mathrm{pH}$ & $87.28 \mathrm{~mL}$ of $\mathrm{HCl} 35.4 \%$ diluted in $1000 \mathrm{~mL}$ \\
\hline
\end{tabular}

An arrangement of three electrodes was employed, utilizing a graphite bar as working electrode (WE) in the A compartment, graphite as counter electrode (CE) and an $\mathrm{Ag} / \mathrm{AgCl}$ electrode as reference electrode (RE) in the $\mathrm{B}$ compartment. For the EIS method application, an SP-150 Bio-Logic Science Instruments $®$ potentiostat was used, employing a frequency range from $100 \mathrm{kHz}$ to $10 \mathrm{mHz}$, at open circuit potential, with 6 points per decade, and $10 \mathrm{mV} / \mathrm{rms}$ of amplitude. These tests were carried out so as to determine electrochemical parameters, water up-take percentage and species diffusion, depending on time, thus allowing making a correlation of results with possible reaction mechanisms produced by the polarization and passage of ions, as well as water absorption across the membrane.

Surface chemical composition analyses of the Chitosan-Gel membranes were performed before and after exposing the membranes to the Body Simulated Kokubo solution used as an electrolyte. Microscopy studies were performed with a JEOL JSM-7600F scanning electron microscope (SEM) equipped with an EDS chemical analyses detector.

\section{Results and discussion}

Impedance diagrams that portray results of the biopolymer membrane interface monitoring, by means of the EIS technique, are shown in Fig. 3. Results 
regarding the first immersion hours in the electrolyte are shown in Fig. 3, as well as results after several exposure days, are shown in Fig. 4.

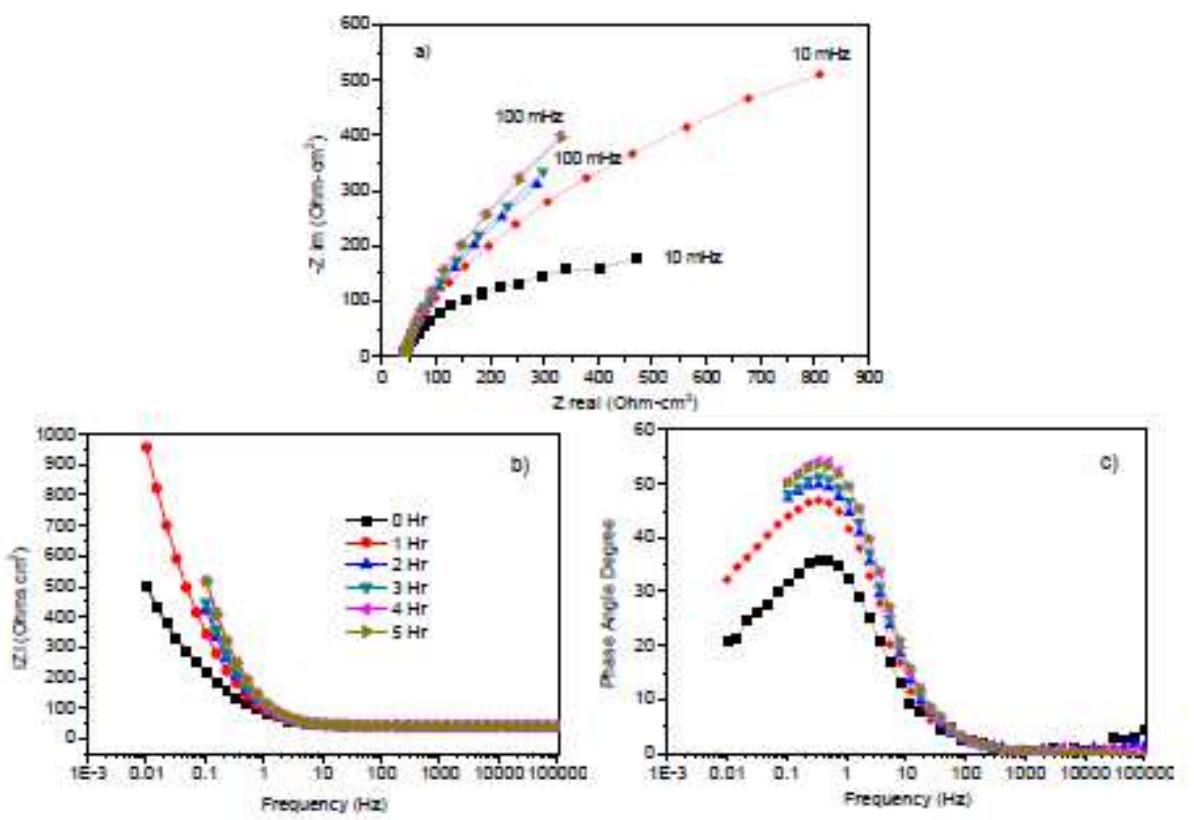

Figure 3. Nyquist diagrams of the membrane as a detached film within the first hours of immersion.

The Nyquist diagrams shown in Fig. 3a portray, as a function of immersion time, a decrease in the real impedance, as a result of ionic species penetration. Such behavior can be more clearly observed in Fig. 4a, where Nyquist diagrams show a capacitive behavior.

In the Bode diagrams (Figs. 3 b-3c and $4 b-4 c$ ) only one time constant can be clearly seen among all the studied frequency ranges.

In order to fit EIS experimental data, the BOUKAMP program [15] was employed, along with the equivalent circuit of Fig. 1, which represents the electrochemical interface formed between the two faces of the biopolymer film and the incursion of the saline solution electrolyte. The fitted parameters are shown in Table 2.
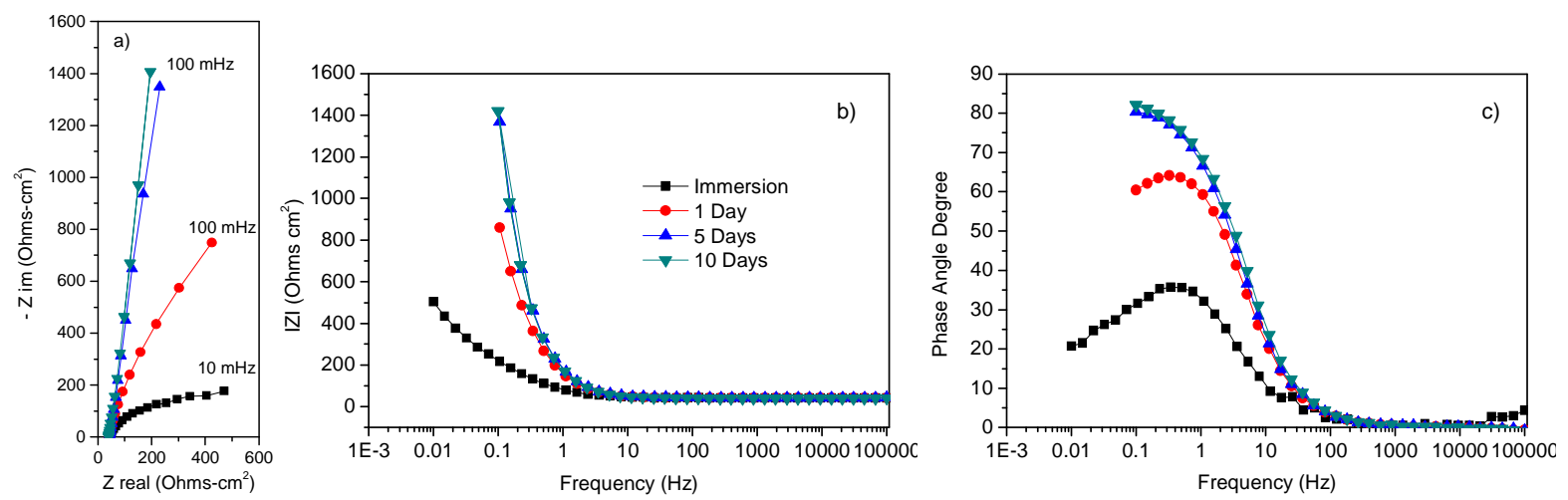

Figure 4. Impedance diagrams of the polymer membrane after several exposure days. 
Table 2. Results from fitting the equivalent circuit of Fig. 1.

\begin{tabular}{cccccccccc}
\hline Time & $\mathbf{R}_{\mathbf{s}}$ & $\mathbf{C}_{\mathbf{f}}$ & $\mathbf{R}_{\mathbf{f a}}$ & $\mathbf{O}_{\mathbf{c}}$ & $\mathbf{B}_{\mathbf{c}}$ & $\mathbf{R}_{\mathbf{f a}}$ & $\mathbf{O}_{\mathbf{a}}$ & $\mathbf{B}_{\mathbf{a}}$ & $\boldsymbol{\chi}^{\mathbf{2}}$ \\
\hline $0 \mathrm{~h}$ & 36.8 & $1.3 \mathrm{E}-5$ & 549 & $3.2 \mathrm{E}-7$ & $1.05 \mathrm{E}-6$ & $6.3 \mathrm{E} 4$ & $8.2 \mathrm{E}-3$ & $1.9 \mathrm{E} 2$ & $9.6 \mathrm{E}-3$ \\
$1 \mathrm{~h}$ & 39.5 & $1.46 \mathrm{E}-3$ & 2450 & $3.1 \mathrm{E}-7$ & $1.37 \mathrm{E}-6$ & - & $9.5 \mathrm{E}-3$ & 39.8 & $3.5 \mathrm{E}-3$ \\
\hline h & 40.1 & $2.32 \mathrm{E}-3$ & 3500 & $1 \mathrm{E}-7$ & $1 \mathrm{E}-6$ & - & $1 \mathrm{E}-3$ & 35 & $3.1 \mathrm{E}-2$ \\
\hline h & 42.8 & $1.75 \mathrm{E}-3$ & 615.5 & $1.84 \mathrm{E}-6$ & $1.5 \mathrm{E}-6$ & - & $7 \mathrm{E}-6$ & 30 & $2.1 \mathrm{E}-2$ \\
\hline
\end{tabular}

The Warburg diffusion coefficients were determined employing equation (5), and they are shown in Table 3.

Table 3. Warburg diffusion coefficients for anodic and cathodic species through the membrane.

\begin{tabular}{rcccc}
\hline Time & $\begin{array}{c}\text { Warburg diffusion } \\
\text { cathodic } \\
\text { coefficient, } \boldsymbol{\sigma}_{\mathbf{c}}\end{array}$ & $\begin{array}{c}\text { Warburg } \\
\text { diffusion anodic } \\
\text { coefficient, } \boldsymbol{\sigma}_{\mathbf{a}}\end{array}$ & $\begin{array}{c}\text { Relationship } \\
\mathbf{R}_{\mathbf{f}, \mathbf{c} / \boldsymbol{\sigma}_{\mathbf{c}}}\end{array}$ & $\begin{array}{c}\text { Relationship } \\
\mathbf{R}_{\mathbf{f}, \mathbf{a}} / \boldsymbol{\sigma}_{\mathbf{a}}\end{array}$ \\
\hline $0 \mathrm{~h}$ & $1.73 \mathrm{E}+06$ & $8.03 \mathrm{E}-01$ & $3.18 \mathrm{E}-04$ & $7.84 \mathrm{E}+04$ \\
\hline $1 \mathrm{~h}$ & $1.53 \mathrm{E}+06$ & $1.63 \mathrm{E}+00$ & $1.60 \mathrm{E}-03$ & ---- \\
\hline $4 \mathrm{~h}$ & $3.16 \mathrm{E}+06$ & $5.35 \mathrm{E}+00$ & $1.11 \mathrm{E}-03$ & ---- \\
\hline $5 \mathrm{~h}$ & $6.02 \mathrm{E}+05$ & $6.90 \mathrm{E}+01$ & $1.02 \mathrm{E}-03$ & ---- \\
\hline $100 \mathrm{~h}$ & ---- & $4.39 \mathrm{E}-01$ & ---- & ---- \\
\hline $240 \mathrm{~h}$ & $1.28 \mathrm{E}+06$ & $1.03 \mathrm{E}+04$ & $7.56 \mathrm{E}-05$ & $7.29 \mathrm{E}-05$ \\
\hline
\end{tabular}

The behaviors of the anodic and cathodic diffusion species across the membrane, as well as the behavior between the resistivity and the diffusivity, are shown in Fig. 5a and Fig. 5b, respectively. The water up-take of the membrane from equation (6) is presented in Fig. 6.

(a)

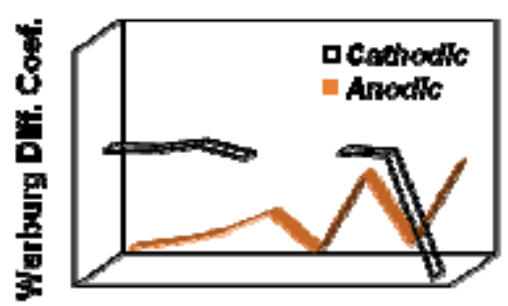

Exposure time, h (b)

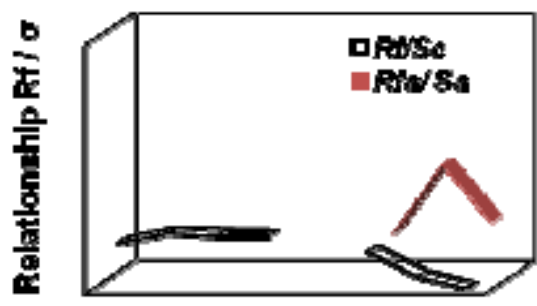

Exposure time, h

Figure 5. (a) Behavior of membrane diffusivity and (b) relationship between resistance and diffusivity for the anodic and cathodic species.

The photographs shown in Fig. 7 show the experimental cell and the physical aspect of membranes, before and after being exposed to the saline solution up to 11 days, whereas Figs. 8 and 9 show the chemical composition of membranes, before and after being exposed to the electrolyte, as well as the SEM microscopy of the morphological surface of the biopolymer membranes. 


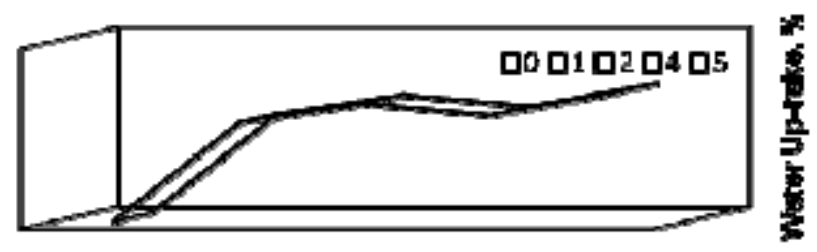

Exposure time, $\mathbf{h}$

Figure 6. Water up-take for the biopolymer membrane of Chitosan-Gel.

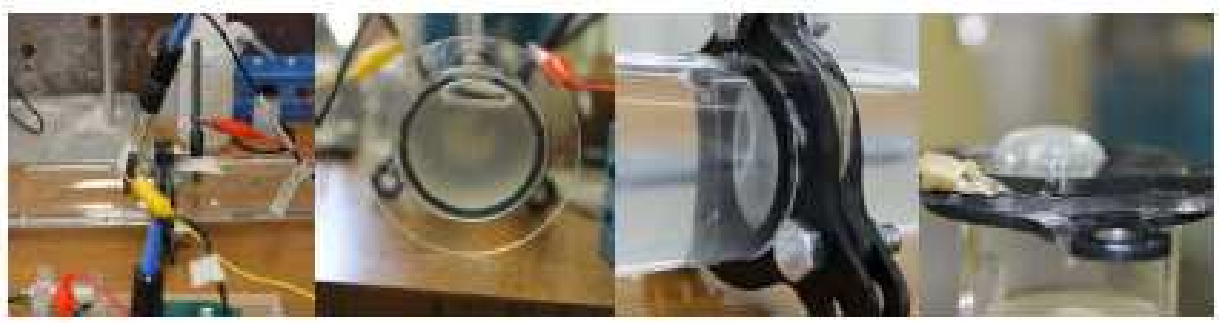

Figure 7. Electrochemical cell to study detached films of Chitosan-Gel.
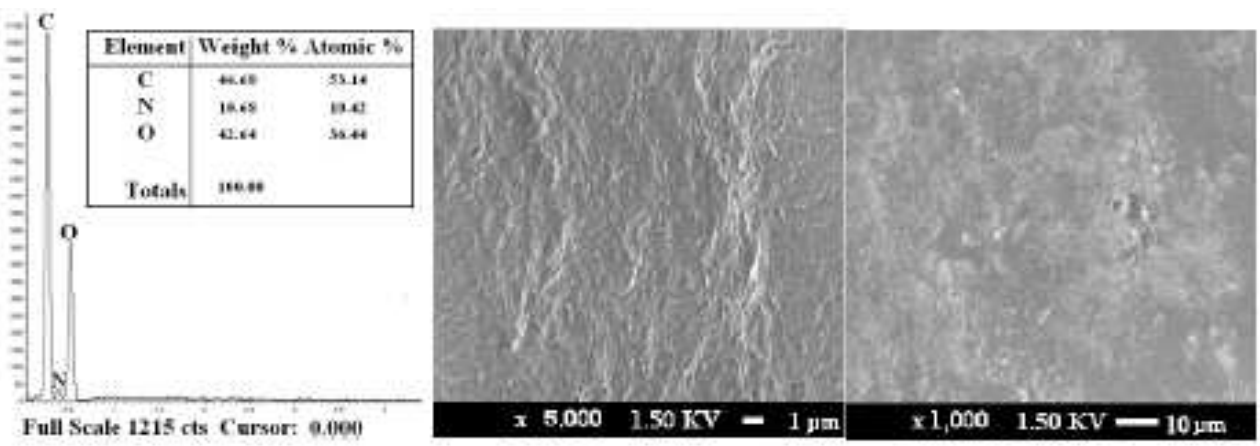

Figure 8. Chemical composition of the Chitosan-Gel films, prior to the exposure to the BSP solution.
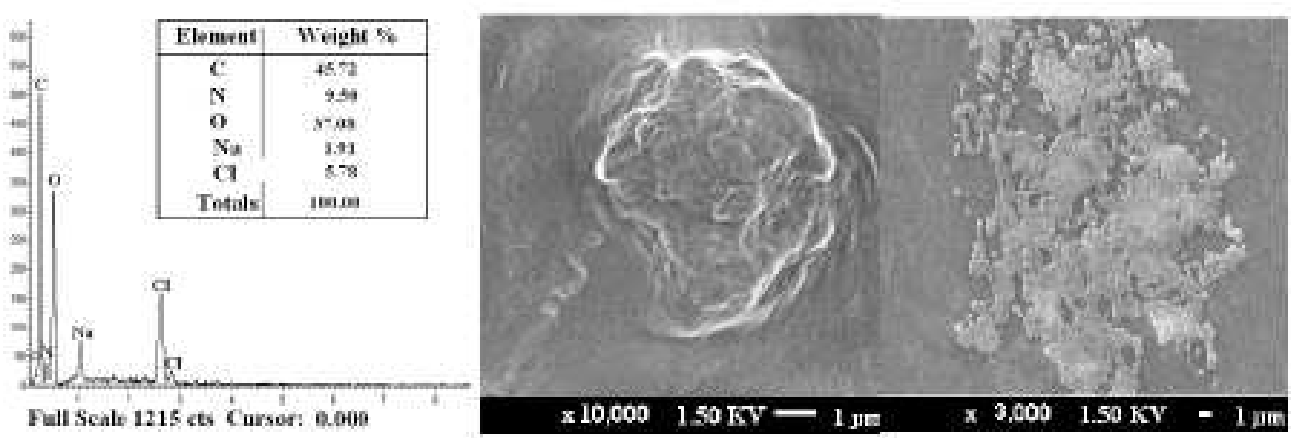

Figure 9. Chemical composition of the Chitosan-Gel films after the exposure to the BSP solution.

The observed behavior in the SEM morphology of membranes showed that, when there is no exposition, the porosity remains stable in both sides of the membrane; nonetheless, after being exposed to the BSP solution, a side of the membrane swollen as a result of the hydrophilic effect attributed to the gelatin, due to the hydrophobic effect attributed to the chitosan matrix. This means that 
the bio-polymer membrane is formed as a two phase system, since the solvent evaporation step affects the porosity, mainly on the gelatin side [18].

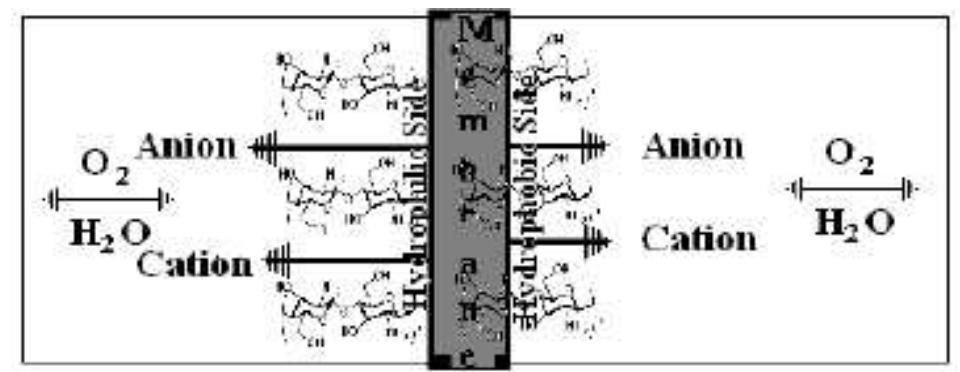

Figure 10. Diagram of ionic species diffusion through the biopolymer membrane.

Detached biopolymer films have been studied, so as to assess their dielectric properties, porosity and waterproofness, when in contact with an electrolyte, using the electrochemical impedance method, as well as the redox mechanism and film biodegradation processes, as shown in Fig. 10.

Studying the membrane under such conditions produces information regarding the behavior of the polymeric structure and its viscoelastic properties, which cause swelling on one side of the membrane, due to the hydrophilic effect, whereas the hydrophobic effect causes swelling on the other side, when it gets into contact with aqueous solutions containing highly ionic species, such as hydroxides and chlorides in physiological solutions.

In our study, it was determined that the film has a very high capacitance $\left(10^{-3}\right.$ $\mathrm{F} / \mathrm{cm}^{2}$ ); moreover, it proved to be highly hygroscopic, since after the first 5 hours of immersion, it reached $75 \%$ of water up-take and, after 24 hours, it was already supersaturated.

Due to the mobility of the ionic species, the redox phenomena can be attributed to the cathodic reaction, which corresponds to the oxygen reduction performed in the cathodic areas of the membrane, as it follows:

$$
\mathrm{H}_{2} \mathrm{O}+\mathrm{H} / 2 \mathrm{O}_{2}+2 e^{-} \rightarrow 2 \mathrm{OH}^{-}
$$

The Chitosan molecule is known for its protonic reactivity, so the $\mathrm{OH}^{-}$of the cathodic reaction (a) could interact promoting a degradation effect on the Chitosan chain, as shown in reaction (b):

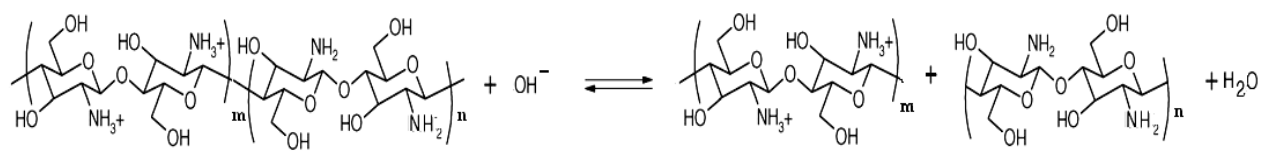

The anodic reaction for $\mathrm{Cl}_{2}$ formation occurs in the membrane's anodic areas, as shown in the following reaction:

$$
2 \mathrm{Cl}^{-} \rightarrow \mathrm{Cl}_{2}+2 e^{-}
$$


Furthermore, an estimation of the Warburg diffusion coefficients, for both reactions occurring across the membrane in both directions, can be obtained, as well as the equivalent circuit with the two proposed branches, which correspond to the cathodic reaction (a) and the anodic reaction (b), with their respective film resistances [11].

In literature, it has been suggested that, when studying paint films as membranes in detached conditions, local resistive areas can be observed, which develop areas of trapped water and ionic species, producing low resistivity, and other areas of high resistivity against the electrolyte's ionic concentration; this is due to various factors, such as the crosslinking degree of the polymer chains [21], membrane porosity or osmotic processes produced by polarization phenomena [22-23].

\section{Conclusions}

The EIS technique is a useful tool for studying electrochemical processes, as well as for evaluating dielectric properties of bio-polymer membranes, and reaction mechanisms that can occur by the incursion of water and ions across the detached film.

With the proposed equivalent circuit, it was possible to determine the influence that can be exerted by the red-ox processes, as well as the resistivity and diffusion phenomena occurring on both sides of the bio-polymer membrane in contact with physiological solutions.

A reaction mechanism of the Chitosan-gel degradation was proposed, promoted by the hydroxide produced with the oxygen reduction, which occurs in the cathodic areas of the Chitosan-gel membrane.

\section{Acknowledgements}

The authors wish to thank the Universidad Veracruzana and its MICRONA Center, for the characterization of the biopolymer, and also to PRODEP, for their support to the project ID 43034.

\section{References}

1. Khor, E. Chitin: Fulfilling a Biomaterials Promise. Oxford: Elsevier; 2001.

2. Pérez B, Sáez E, Martínez G, et al. Polímeros biodegradables en el transporte selectivo de moléculas antitumorales. ARS Pharm 51, Suplemento 3; 2010. p. 171-6.

3. Sahoo R, Sahoo S, Lochan P. Eur Sci J. 2013;9:135.

4. González JB, Prokhorov E, Luna G, et al. J Polym Sci. 2009;47:2259.

5. Viciosa MT, Dionisio M, Silva RM, et al. Biomacromolecules. 2004;5:2073.

6. Gonzalez JB, Prokhorov E, Luna G, et al. Polym Sci Part B: Polym Phys. 2009;47:932.

7. Mac Donald JR. Impedance Spectroscopy. New York: Willey Interscience; 1987. 
8. Epelboin I, Keddam M, Gabrielli C, et al. Progress in Electrochem. Corrosion Testing, ASTM Symp. May (1979), Ed. By Mansfeld and Bertucci, 1981:150.

9. Tribollet B, Newman J, Smyrl W. J Electrochem Soc Electrochemical Sci Technol. 1988;135:134.

10. Armstrong RD, Bell MF, Metcalfe AA. The A. C. Impedance of complex electrochemical reactions", a Specialist Periodical Report, Vol. 6 Thirsk H. (Senior reporter). London: The Chemical Society; 1978.

11. Ramírez-Reyes JL. PhD Dissertation. Manchester Victoria University, UMIST, Manchester UK; 1994.

12. Thomas JGN. The use of Impedance Spectroscopy for the study of Coated Metals. A Review. UK: Paint Research Assoc; 1990.

13. Dawson JL, John DG. J Electroanal Chem Interf Electrochem. 1980;110:37.

14. Ramírez Reyes JL, Turgoose S. "Estudios de impedancia electroquímica sobre películas despegadas.. Cong Int de Materiales. Cancun QR, México; 2002.

15. Boukamp B. Equivalent Circuit Software. Twente: University of Twente, Neeterlands; 1989.

16. Van Beek LKH. Prog Dielectrics. 1967;7:69.

17. Bellucci F, Nicodemo L. Corrosion. 1993;49:235.

18. Quintana H, Hernández T, Galicia G, et al. Sintesis de películas de Quitosano-Grenetina como recubrimiento para uso Biomédico. México: ICA-Nano-2014; 2014.

19. Kokubo T, Takadama, H. Biomaterials. 2006;27:2907.

20. Kokubo T, Kushitani H, Sakka T, et al. J Biomed Mater Res. 1990;24:721.

21. Liu B, Fang Z, Wang H, et al. Prog in Org Coatings. 2013;76:1814.

22. Sussex JAM, Scantlebury JD. JOOCA. 1983;142.

23. Leidheiser Jr H. ACS Symp Series. 1986;332:124. 